\title{
Chemical Characterization of Kraft Lignin Prepared from Mixed Hardwoods
}

\author{
Ji-Sun Mun ${ }^{1}\left(\mathbb{D}\right.$, Justin Alfred Pe III ${ }^{2} \mathbb{D}$ and Sung-Phil Mun ${ }^{2, *}$ \\ 1 Department of Carbon Materials and Fiber Engineering, Jeonbuk National University, Jeonju 54896, Korea; \\ jismun20@jbnu.ac.kr \\ 2 Department of Wood Science and Technology, Jeonbuk National University, Jeonju 54896, Korea; \\ justinpe@jbnu.ac.kr \\ * Correspondence: msp@jbnu.ac.kr
}

Citation: Mun, J.-S.; Pe, J.A.; Mun, S.-P. Chemical Characterization of Kraft Lignin Prepared from Mixed Hardwoods. Molecules 2021, 26, 4861. https://doi.org/10.3390/ molecules26164861

Academic Editors:

Łukasz Klapiszewski and

Teofil Jesionowski

Received: 20 July 2021

Accepted: 7 August 2021

Published: 11 August 2021

Publisher's Note: MDPI stays neutral with regard to jurisdictional claims in published maps and institutional affiliations.

Copyright: (C) 2021 by the authors. Licensee MDPI, Basel, Switzerland. This article is an open access article distributed under the terms and conditions of the Creative Commons Attribution (CC BY) license (https:/ / creativecommons.org/licenses/by/ $4.0 /)$.

\begin{abstract}
Chemical characterization of kraft lignin (KL) from mixed hardwoods (Acacia spp. from Vietnam and mixed hardwoods (mainly Quercus spp.) from Korea) was conducted for its future applications. To compare the structural changes that occurred in KL, two milled wood lignins (MWLs) were prepared from the same hardwood samples used in the production of KL. Elemental analysis showed that the MWL from acacia (MWL-aca) and mixed hardwood (MWL-mhw) had almost similar carbon content, methoxyl content, and $\mathrm{C}_{9}$ formula. KL had high carbon content but low oxygen and methoxyl contents compared to MWLs. The $\mathrm{C}_{9}$ formula of KL was determined to be $\mathrm{C}_{9} \mathrm{H}_{7.29} \mathrm{O}_{2.26} \mathrm{~N}_{0.07} \mathrm{~S}_{0.12}\left(\mathrm{OCH}_{3}\right)_{1.24}$. The $\mathrm{M}_{\mathrm{W}}$ of $\mathrm{KL}$ and MWLs was about 3000 Da and 12,000-13,000 Da, respectively. The structural features of KL and MWLs were investigated by Fourier transform infrared spectroscopy (FT-IR) and nuclear magnetic resonance spectrometry $\left({ }^{1} \mathrm{H},{ }^{13} \mathrm{C}\right.$ NMR). The analyses indicated that KL underwent severe structural modifications, such as $\gamma$-carbon cleavage, demethylation, and polycondensation reactions during kraft pulping, which resulted in increased aromatic content and decreased aliphatic content. The main linkages in lignin, $\beta-\mathrm{O}-4$ moieties, were hardly detected in the analysis as these linkages were extensively cleaved by nucleophilic attack of $\mathrm{SH}^{-}$and $\mathrm{OH}^{-}$during pulping.
\end{abstract}

Keywords: kraft lignin; acacia; mixed hardwood; milled wood lignin; structural analysis

\section{Introduction}

Lignin is the second-most abundant organic carbon source after cellulose. The amount of lignin discharged is about 50-70 million tons annually [1,2]; however, it has been estimated that only a small amount (ca. $1-2 \%$ ) is used in specialty products [3]. Lignin can be obtained by pulping and kraft pulping accounts for about $85 \%$ of the total lignin production [4]. The lignin recovered from the black liquor after kraft pulping is called kraft lignin. The majority of KLs are directly burned in pulp mills to generate energy and to recover the remaining pulping chemicals, while some KLs are used as rubber additives and phenolic resin adhesives [5,6]. Limitations on the utilization of KLs are due to their heterogeneity, modified structure, presence of sulfur from sodium sulfide, and the poor quality of the final product $[7,8]$.

Along with KL, lignosulfonates (LS) are commercially available lignins that have been used for a long time in the production of vanillin, dispersant, coagulant, etc. [9]. Although KL is less utilized than LS, KL is still an attractive resource for researchers and pulping companies since it is cheap, renewable, and available in large amounts. Therefore, converting KL into a high value-added material is one major research goal, even though the use of KL is currently limited. Studies on the application of KL as bioadhesives [10], supercapacitors [11], fuel for fuel cells [12], polyurethane foams [13], and carbon fibers [14] have been conducted recently. However, few applications were commercially profitable [8], and further studies are needed for the mass consumption of KL. In addition, converting 
lignin into value-added products is one way to unleash its potential [7]. Particularly, in the near future, massive amounts of lignin will be derived as a by-product since many researchers are trying to use lignocellulosic biomass for the production of bioethanol or biosugar. If a beneficial way to use KL is developed, the utilization of less structurally modified lignins from bioethanol and biosugar production will become easier as well.

Since KL is an underutilized resource, the purpose of this study was to investigate the chemical characteristics of KL from mixed hardwoods to proceed to further applications involving new value-added lignin-based products, such as carbon materials, fine chemicals, and dyestuffs. Most studies on the characterization of KL focused on softwood KL rather than hardwood KL. Hence, this study reports the characterization of KL from mixed hardwoods. Moreover, little emphasis was given to the comparison of hardwood KL and MWLs with respect to the structural changes that occurred in lignin. Therefore, in this study, KL was compared to MWLs prepared from the same hardwood samples used for kraft pulping.

\section{Results and Discussion}

\subsection{Chemical Composition of Acacia and Mixed Hardwood}

The results of alcohol-benzene extract and total lignin contents of acacia and mixed hardwood are shown in Table 1. The alcohol-benzene extract contents were $1.51 \%$ for acacia and $1.60 \%$ for mixed hardwood, showing slightly comparable values. The total lignin content of acacia was $26.90 \%$ which was slightly higher than mixed hardwood $(24.76 \%)$. In general, it is known that the lignin content of tropical hardwoods is comparable to that of temperate softwoods [9]. As acacia species are grown in tropical or subtropical regions like Vietnam, the total lignin content of acacia was higher.

Table 1. Chemical composition of wood meals used in MWL preparation.

\begin{tabular}{ccc}
\hline & Acacia spp. & Mixed Hardwood \\
\hline Alcohol-benzene extract (\%) & 1.51 & 1.60 \\
Lignin (\%) & & \\
Klason & $24.69 \pm 0.11$ & $21.23 \pm 0.25$ \\
Acid-soluble & $2.21 \pm 0.01$ & $3.53 \pm 0.09$ \\
Total & $26.90 \pm 0.11$ & $24.76 \pm 0.25$ \\
\hline
\end{tabular}

\subsection{Elemental Composition of $K L$ and $M W L s$}

The $\mathrm{C}, \mathrm{H}, \mathrm{O}, \mathrm{N}, \mathrm{S}$, and $\mathrm{OCH}_{3}$ content of $\mathrm{KL}$ and MWLs are summarized in Table 2. The methoxyl content was estimated using the integration ratio of protons derived from the aromatic and the methoxyl groups in the ${ }^{1} \mathrm{H}$ NMR as described by Abreu [15]. KL was not only chemically modified during kraft pulping, but new elements were introduced. Considerable amounts of sulfur were present in KL unlike in the MWLs, as kraft pulping chemical $\left(\mathrm{Na}_{2} \mathrm{~S}\right)$ was directly involved in lignin depolymerization which generated sulfide ions during pulping. In addition, as shown in Table 2, KL had higher carbon content, and lower oxygen and methoxyl contents compared to MWLs.

Table 2. Elemental analyses and methoxyl contents of KL and MWLs.

\begin{tabular}{ccccccc}
\hline \multirow{2}{*}{ Lignin Type } & \multicolumn{7}{c}{ Elemental Analyses (\%) } \\
\cline { 2 - 7 } & $\mathbf{C}$ & $\mathbf{H}$ & $\mathbf{O}$ & $\mathbf{N}$ & $\mathbf{S}$ & $\mathbf{O C H}_{\mathbf{3}}$ \\
\hline KL & 63.12 & 5.67 & 28.78 & 0.48 & 1.96 & 19.80 \\
MWL-aca & 57.34 & 5.62 & 37.04 & - & - & 21.92 \\
MWL-mhw & 57.38 & 5.75 & 36.71 & 0.16 & - & 21.75 \\
\hline
\end{tabular}

Methoxyl content was calculated by the integrations of the aromatic and methoxyl signals in ${ }^{1} \mathrm{H}$ NMR spectrum [15]

The $\mathrm{C}_{9}$ molecular formula, $\mathrm{C}_{9}$ molecular weight, and double bond equivalent (DBE) of KL and MWLs are listed in Table 3. The DBE approximates the number of double bonds and the presence of cyclic structures together with the frequency of interunit linkages in a 
phenylpropane $\left(C_{9}\right)$ unit $[16,17]$. The calculated DBE values revealed that in comparison to MWLs, KL contained a high degree of unsaturation as a consequence of the transformation of lignin moieties (i.e., $\beta-O-4, \beta-\beta, \beta-1, \beta-5,5-5$, and 4-O-5) into their condensed forms with newly incorporated double bonds. Table 3 also shows that KL had a lower $C_{9}$ MW than MWLs. These outcomes suggest that the original lignin was depolymerized into lignin fragments which were condensed and contained high degree of unsaturation. These results are also in agreement with well-established reactions of model lignin compounds.

Table 3. $\mathrm{C}_{9}$ formula, $\mathrm{C}_{9} \mathrm{MW}$, and DBE of KL and MWLs.

\begin{tabular}{cccc}
\hline Lignin Type & $\mathrm{C}_{\mathbf{9}}$ Formula & $\mathrm{C}_{\mathbf{9}}$ MW (Da) & DBE \\
\hline KL & $\mathrm{C}_{9} \mathrm{H}_{7.29} \mathrm{O}_{2.26} \mathrm{~N}_{0.07} \mathrm{~S}_{0.12}\left(\mathrm{OCH}_{3}\right)_{1.24}$ & 194.9 & 5.74 \\
MWL-aca & $\mathrm{C}_{9} \mathrm{H}_{7.61} \mathrm{O}_{3.56}\left(\mathrm{OCH}_{3}\right)_{1.56}$ & 221.2 & 5.42 \\
MWL-mhw & $\mathrm{C}_{9} \mathrm{H}_{7.93} \mathrm{O}_{3.52} \mathrm{~N}_{0.03}\left(\mathrm{OCH}_{3}\right)_{1.55}$ & 220.9 & 5.26 \\
\hline
\end{tabular}

${ }^{*}$ DBE: double bond equivalent.

Studies on structural modifications during kraft pulping indicated that $\beta-\mathrm{O}-4$ structures, with hydroxyl or carbonyl groups attached at the $\alpha$ or $\gamma$ positions, underwent $\beta$-ether cleavage, resulting in styrene-like compounds, which then further degraded leading to side chain cleavage at the $\alpha, \beta$, or $\gamma$-carbon positions as shown in Figure $1[18,19]$. The splitting of the side chain from the $\mathrm{C}_{9}$ unit caused a reduced $\mathrm{C}_{9} \mathrm{MW}$ for KL. Also, linkages involving side chain cleavage at the $\gamma$-carbon position produced formaldehyde which eventually reacted with other lignols to form condensed products like diphenylmethane [20]. These condensed products increased the carbon content of KL. The demethylation reaction caused by the attack of sulfide ions to the methoxyl group at C-3 or C-5 resulted in the formation of methylmercaptan $\left(\mathrm{CH}_{3} \mathrm{SH}\right)$ and then further oxidation produced dimethyldisulfide $\left(\mathrm{CH}_{3} \mathrm{SSCH}_{3}\right)$ [21]. The demethylation caused reduced methoxyl content for KL compared to MWLs.<smiles>[R]c1cc(C(O)[C@H](CO)Oc2c(C)cc(C)cc2OC)cc(OC)c1O</smiles>

$\mathrm{R}=\mathrm{H}$ (guaiacyl) or $\mathrm{OCH}_{3}$ (syringyl)

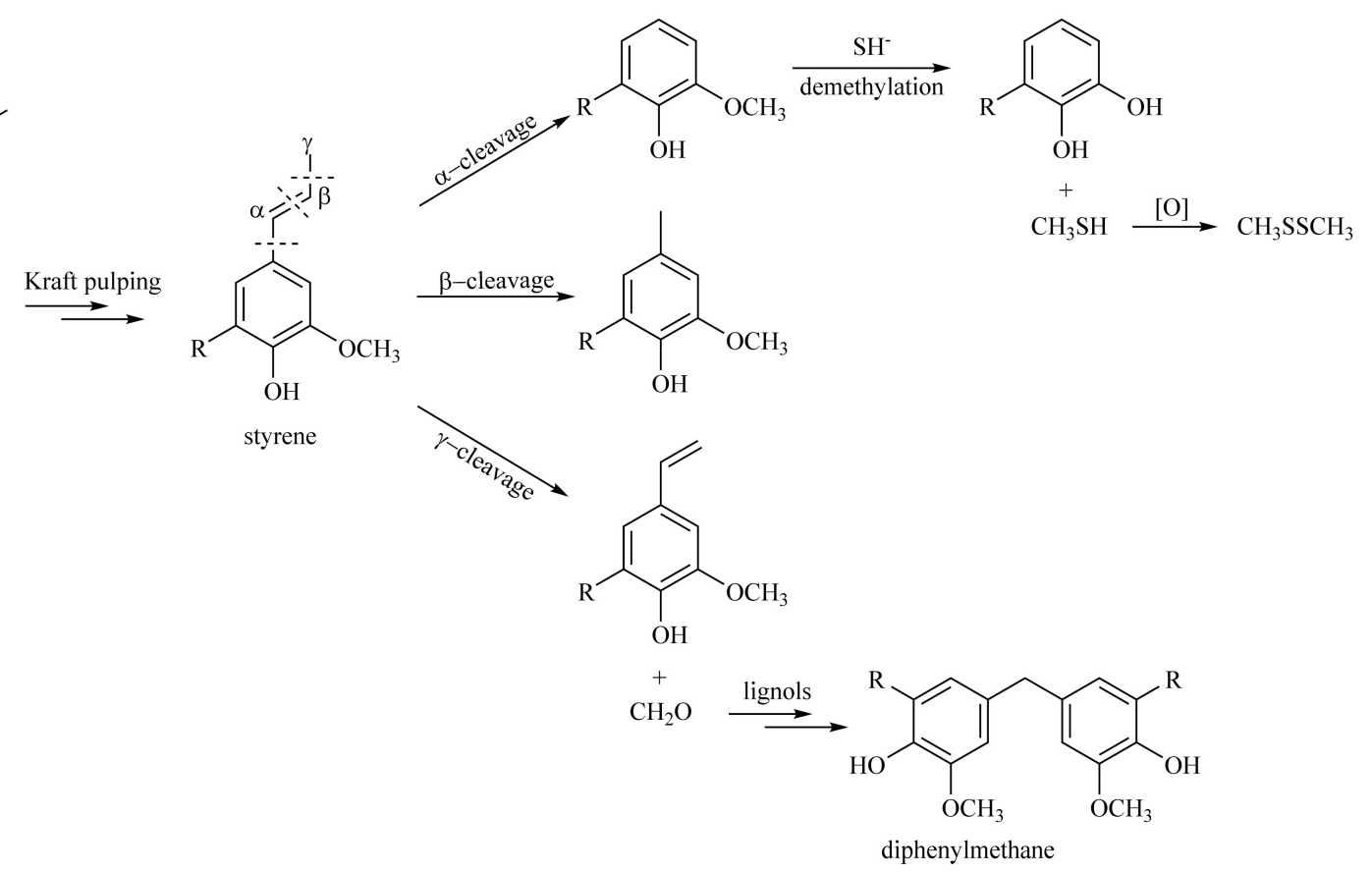

Figure 1. Behavior of $\beta-\mathrm{O}-4$ linkages during kraft pulping.

\subsection{MW Distribution, Average MW, and Polydispersity}

The weight-average $\left(M_{W}\right)$ and number-average $\left(M_{n}\right) M W$, and polydispersity index (PDI) of acetylated KL (Ac-KL) and acetylated MWLs (Ac-MWLs) were determined by gel permeation chromatography (GPC). The MW distribution of Ac-KL and Ac-MWLs are 
shown in Figure 2 while the $M_{w}, M_{n}$, and PDI are given in Table 4. As shown in Figure 2, the MW distributions of KL and MWL were very different. In the case of KL, the low MW (less than 10,000) fractions were predominant, and in particular, two peaks were observed at a MW of 1000 or less. On the other hand, the MW distribution of the two types of MWLs had no remarkable difference.

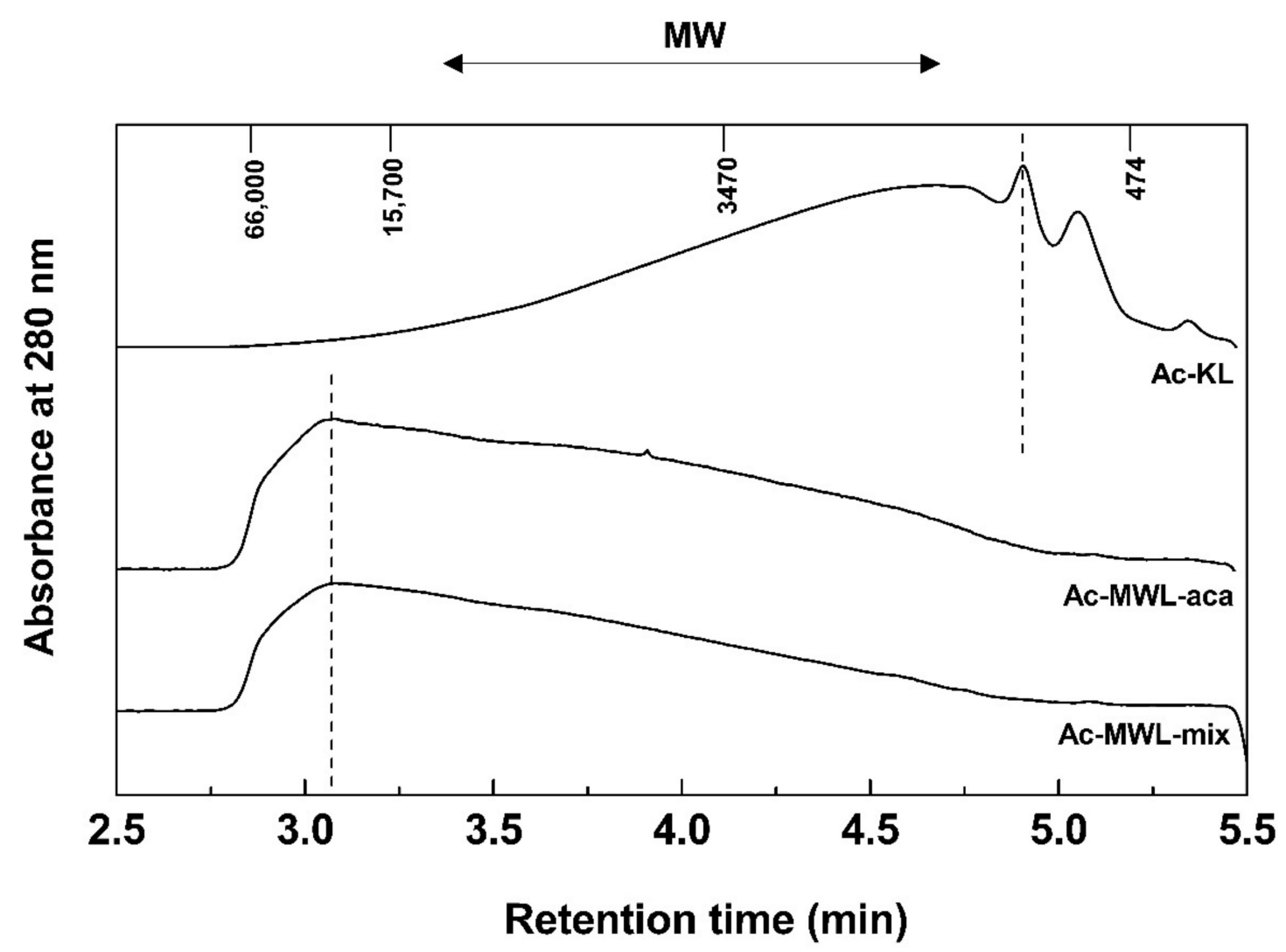

Figure 2. MW distribution of Ac-KL and Ac-MWLs.

Table 4. Average MW and PDI of Ac-KL and Ac-MWL.

\begin{tabular}{cccc}
\hline & $\mathbf{M}_{\mathbf{w}}(\mathbf{D a})$ & $\left.\mathbf{M}_{\mathbf{n}} \mathbf{( D a}\right)$ & PDI \\
\hline Ac-KL & 3041 & 1651 & 1.8 \\
Ac-MWL-aca & 11,898 & 4416 & 2.7 \\
Ac-MWL-mhw & 13,314 & 5657 & 2.4 \\
\hline
\end{tabular}

As shown in Table 4, the $\mathrm{M}_{\mathrm{w}}$ of KL and MWLs was about $3000 \mathrm{Da}$ and 12,000-13,000 Da, respectively. These MWs were similar to those of the previously reported hardwood KL and MWL [22]. KL had a $\mathrm{M}_{\mathrm{w}}$ of about $1 / 4$ and a $\mathrm{M}_{\mathrm{n}}$ of 1/3-1/4 with respect to MWLs. Moreover, KL had lower PDI than MWLs. The result indicates that molecules in the original lignin were highly degraded during kraft pulping.

\subsection{FT-IR Analysis}

The FT-IR spectra of KL and MWLs are shown in Figure 3 and the assignments, according to Faix [23], are given in Table 5. The overall FT-IR spectral pattern of KL was similar to MWL. However, absorption bands around $1720-1730 \mathrm{~cm}^{-1}$, corresponding to ester bonds, were not observed which indicates that the ester bonds were severely cleaved by $\mathrm{NaOH}$ and $\mathrm{Na}_{2} \mathrm{~S}$ in highly alkaline conditions during kraft pulping. In general, the basic aromatic nucleus structure of hardwood lignin consists of guaiacyl $(G)$ units and syringyl (S) units. In the case of MWL, a distinct absorption band was observed at 
$1020-1330 \mathrm{~cm}^{-1}$, indicating the presence of these units. Specifically, the absorption bands related to the $S$ units appeared around 1325, 1220 and $1120 \mathrm{~cm}^{-1}$, and 1275 and $1030 \mathrm{~cm}^{-1}$ for the $\mathrm{G}$ units. However, for $\mathrm{KL}$, a shoulder appeared at $1275 \mathrm{~cm}^{-1}$ and a weak absorption band was observed at $1030 \mathrm{~cm}^{-1}$. These results suggest that $\mathrm{G}$ and $\mathrm{S}$ units were present in KL but might have been significantly degraded or modified compared to MWL. The methoxyl content in KL was low similar to the result of EA. From the FT-IR analysis, it was confirmed that the side chains and aromatic nuclei of KL were chemically modified during kraft pulping.

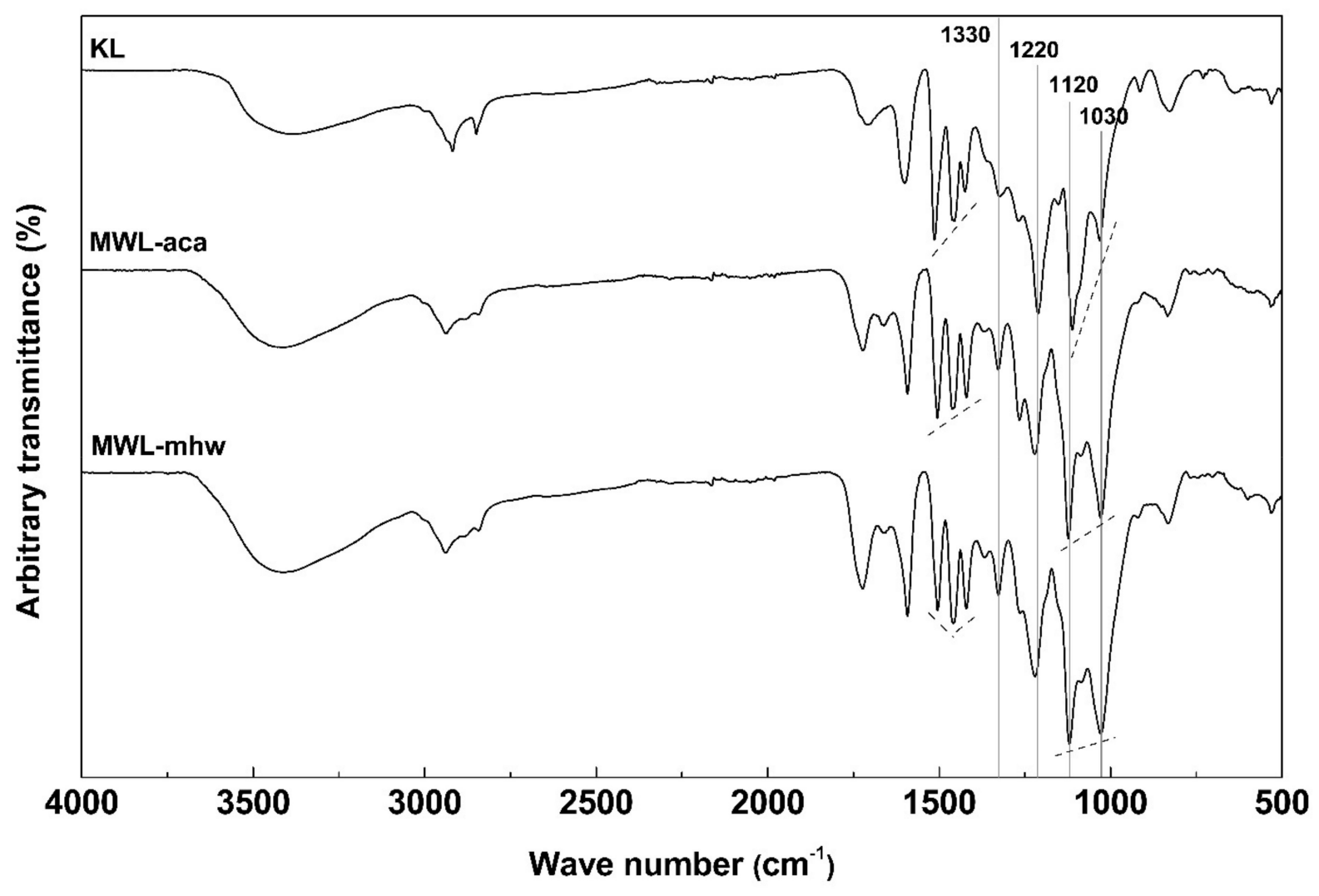

Figure 3. FT-IR ATR spectra of KL and MWLs.

\section{5. ${ }^{1} \mathrm{H}$ NMR Analysis}

The ${ }^{1} \mathrm{H}$ NMR spectra of Ac-KL were compared to Ac-MWLs from acacia and mixed hardwood (Figure 4). The aromatic region (7.20-6.25 ppm) revealed the presence of $\mathrm{G}$ and $\mathrm{S}$ phenylpropane $\left(\mathrm{C}_{9}\right)$ units. Structural changes were shown in the methoxyl (4.00-3.48 ppm), acetyl (2.50-1.60 ppm), and hydrocarbon regions (1.40-0.70 ppm). Table 6 shows the assignments of signal in the ${ }^{1} \mathrm{H}$ NMR spectra of Ac-lignins based on literature data $[24,25]$. The distribution of protons per $C_{9}$ structural unit of Ac-lignins was estimated via integration ratios and their $\mathrm{C}_{9}$ molecular formulas [26]. The methoxyl content in the $\mathrm{C}_{9}$ molecular formula for KL was 1.24, multiplied by 3 to obtain 3.72, the total number of protons $(\mathrm{H})$ in the methoxyl groups. Integration values of other structural components were made relative to the methoxyl protons in one $C_{9}$ unit. However, some quantitative conclusions could not be confirmed due to overlapping signals, carbohydrate inclusions, and uncertainties in range assignments.

The arylglycerol $\beta-O-4$ aryl ether linkage (6.25-5.75 ppm, 4.90-4.30 ppm) is the main intermonomeric linkage found in native lignin [24] and is estimated to be about $60-70 \%$ of hardwoods. The resonances of the $\mathrm{H}_{\alpha}$ and $\mathrm{H}_{\beta}$ in acetylated $\beta-\mathrm{O}-4$ structures at the specified range were hardly detected in $\mathrm{Ac}-\mathrm{KL}$ as severe $\beta-\mathrm{O}-4$ bond hydrolysis occurred during kraft pulping wherein the $\beta-O-4$ structures were transformed to styrene-like structures [18]. 
Further reactions caused bond cleavage at the $\gamma$-carbon position, releasing formaldehyde and forming condensation products, such as diphenylmethanes [20].

Table 5. Assignment of FT-IR spectra of KL and MWLs.

\begin{tabular}{|c|c|c|c|c|}
\hline Peak Range, $\mathrm{cm}^{-1}$ & Assignment & KL & MWL-aca & MWL-mhw \\
\hline $3412-3460$ & $\mathrm{O}-\mathrm{H}$ stretching & 0 & O & 0 \\
\hline $2842-3000$ & $\mathrm{C}-\mathrm{H}$ stretching in methyl, methylene, and methine groups & 2916-2849 & $2938-2844$ & $2939-2844$ \\
\hline $1709-1738$ & $\mathrm{C}=\mathrm{O}$ stretching in unconjugated ketone and ester group & 1731,1707 & 1723 & 1721 \\
\hline $1655-1675$ & $\mathrm{C}=\mathrm{O}$ stretching in conjugated $p$-substituted aryl ketone & - & 1663 & 1660 \\
\hline $1593-1605$ & $\begin{array}{l}\text { Aromatic skeleton vibration plus } \mathrm{C}=\mathrm{O} \text { stretching; } \mathrm{S}>\mathrm{G} \text { : } \\
\qquad \mathrm{G}_{\text {condensed }}>\mathrm{G}_{\text {etherified }}\end{array}$ & 1603 & 1592 & 1592 \\
\hline $1505-1515$ & Aromatic skeleton vibration $(\mathrm{G}>\mathrm{S})$ & 1513 & 1505 & 1505 \\
\hline $1460-1470$ & $\mathrm{C}-\mathrm{H}$ deformations (asymm in $-\mathrm{CH}_{3}$ and $-\mathrm{CH}_{2}-$ ) & 1457 & 1462 & 1457 \\
\hline $1422-1430$ & $\begin{array}{c}\begin{array}{c}\text { Aromatic skeleton vibration combined with } \mathrm{C}-\mathrm{H} \text { in plane } \\
\text { deformations }\end{array}\end{array}$ & 1422 & 1420 & 1421 \\
\hline $1365-1370$ & Aliphatic $\mathrm{C}-\mathrm{H}$ stretching in $\mathrm{CH}_{3}$ and phenolic $\mathrm{OH}$ & - & 1369 & 1367 \\
\hline $1325-1330$ & Condensed $S$ and $G$ ring ( $G$ ring bound via position 5 ) & 1320 & 1328 & 1327 \\
\hline $1266-1270$ & $\mathrm{G}$ ring plus $\mathrm{C}+\mathrm{O}$ stretching (G-methoxyl $\mathrm{C}-\mathrm{O}$ ) & 1267 & 1266 & 1265 \\
\hline $1221-1230$ & $\mathrm{C}-\mathrm{C}+\mathrm{C}-\mathrm{O}+\mathrm{C}=\mathrm{O}$ stretching $\left(\mathrm{G}_{\text {condensed }}>\mathrm{G}_{\text {etherified }}\right)$ & 1210 & 1221 & 1223 \\
\hline 1116 & Typical for HGS lignins; $\mathrm{C}=\mathrm{O}$ in ester groups (conj.) & 1110 & 1123 & 1120 \\
\hline 1086 & C-O deformation in sec-alcohols and aliphatic ether & - & 1089 & 1084 \\
\hline $1030-1035$ & $\begin{array}{c}\text { Aromatic C-H in-plane deformation }(\mathrm{G}>\mathrm{S})+\mathrm{C}-\mathrm{O} \\
\text { deformation in primary alcohols }+\mathrm{C}-\mathrm{H} \text { stretching } \\
\text { (unconjugated) }\end{array}$ & 1034 & 1029 & 1029 \\
\hline $915-925$ & $\mathrm{C}-\mathrm{H}$ out of plane (aromatic ring) & 914 & - & 920 \\
\hline $834-835$ & $\mathrm{C}-\mathrm{H}$ out of plane in positions ( 2 and 6 of $\mathrm{S}$ units) & - & 834 & - \\
\hline $817-832$ & $\mathrm{C}-\mathrm{H}$ out of plane in positions $(2,5$, and 6 of $\mathrm{G}$ units $)$ & 827 & - & 832 \\
\hline
\end{tabular}

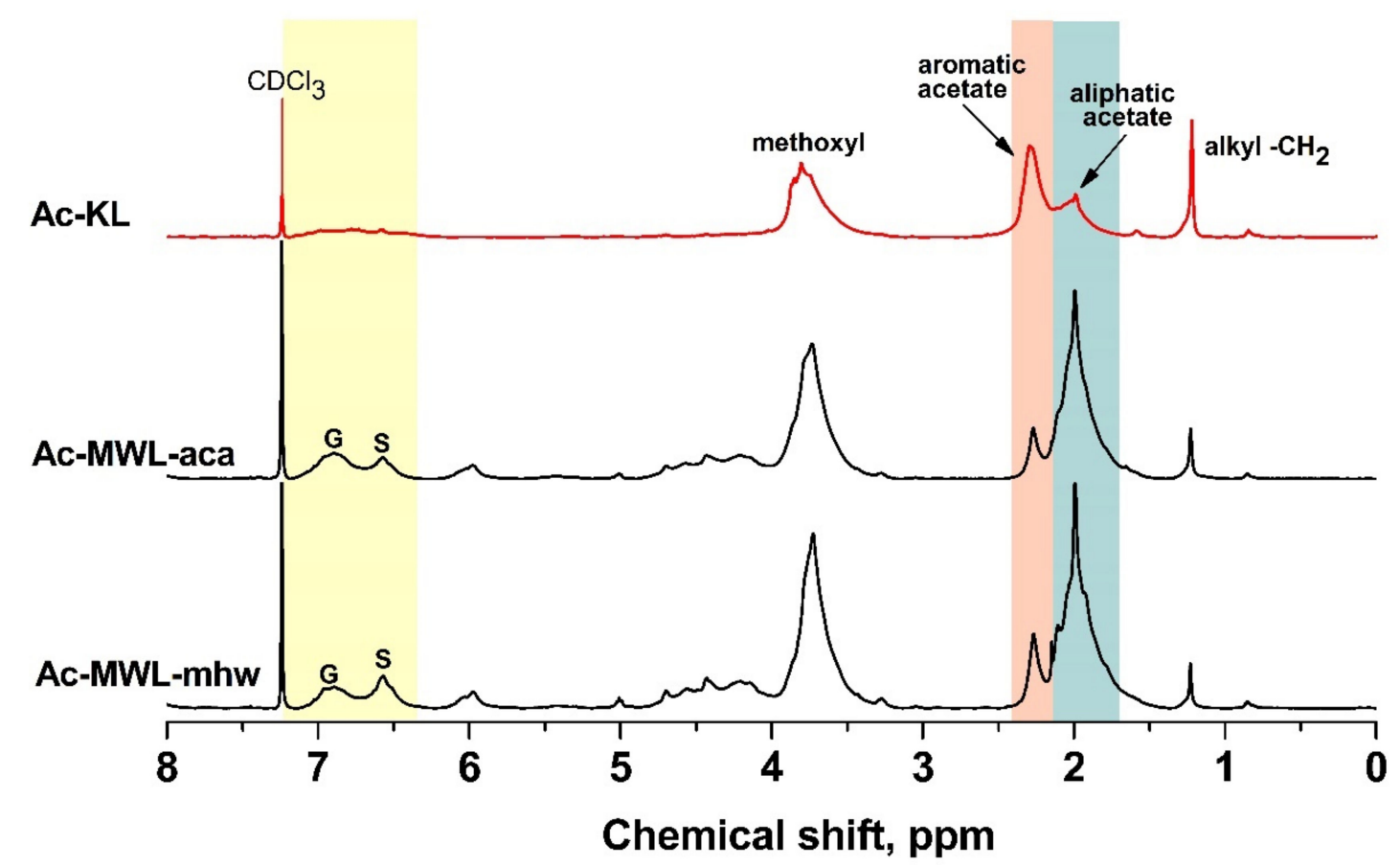

Figure 4. ${ }^{1} \mathrm{H}$ NMR spectra of Ac-lignins.

The aromatic protons per $\mathrm{C}_{9}$ unit for Ac-KL were 0.52 for $\mathrm{S}$ units and 0.37 for $\mathrm{G}$ units, while for Ac-MWL-mhw the aromatic protons per $\mathrm{C}_{9}$ unit were 0.84 for $\mathrm{S}$ units and 0.57 for $G$ units. Comparing the integration values of Ac-KL to Ac-MWLs, the decreased number of aromatic protons indicated a highly condensed structural motif in KL. The integration values were converted to their molar counterparts to estimate the $S$ to $G$ 
molar ratio. As shown in Table 7, the S/G molar ratio of Ac-KL was almost similar to Ac-MWL-mhw. A further step of calculation showed the $S$ and $G$ composition in terms of percentage composition. In the case of $\mathrm{KL}$, the $\% \mathrm{~S}$ units were derived from the formula: $3.37 /(2.98+3.37) \times 100$, which yielded $53.1 \%$.

Table 6. ${ }^{1} \mathrm{H}$ NMR assignments and distribution of protons per $\mathrm{C}_{9}$ structural unit of acetylated lignins.

\begin{tabular}{|c|c|c|c|c|}
\hline \multirow{2}{*}{ Range, ppm } & \multirow{2}{*}{ Main Assignments } & \multicolumn{3}{|c|}{ Protons per $\mathrm{C}_{9}$ Units } \\
\hline & & Ac-KL & Ac-MWL-aca & Ac-MWL-mhw \\
\hline $7.20-6.80 *$ & Aromatic proton in $\mathrm{G}$ units & 0.37 & 0.84 & 0.57 \\
\hline $6.80-6.25$ & Aromatic proton in $S$ units & 0.52 & 0.72 & 0.84 \\
\hline $6.25-5.75$ & $\mathrm{H}_{\alpha}$ of $\beta-\mathrm{O}-4$ and $\beta-1$ structures & - & 0.31 & 0.33 \\
\hline $4.90-4.30$ & $\mathrm{H}_{\alpha} \& \mathrm{H}_{\beta}$ of $\beta-\mathrm{O}-4$ structures & 0.17 & 1.09 & 1.09 \\
\hline $4.30-4.00$ & $\mathrm{H}_{\alpha}$ of $\beta-\beta$ structures, $\mathrm{H}$ of xylan residues & 0.25 & 0.85 & 0.83 \\
\hline $4.00-3.48$ & $\mathrm{H}$ of methoxyl groups & 3.72 & 4.68 & 4.65 \\
\hline $2.50-2.22$ & $\mathrm{H}$ of phenolic acetates & 2.54 & 0.65 & 0.83 \\
\hline $2.22-1.60$ & $\mathrm{H}$ of aliphatic acetates & 2.22 & 5.33 & 5.42 \\
\hline $1.40-0.70$ & Hydrocarbon & 0.76 & 0.31 & 0.19 \\
\hline
\end{tabular}

${ }^{*}$ From reference it was $7.25-6.80$ but $\mathrm{CDCl}_{3}$ solvent peak was detected at 7.24 , thus the range was shifted.

Table 7. Estimation of $S$ units, G units, and S/G ratio in terms of moles and percentage.

\begin{tabular}{ccccccc}
\hline \multirow{2}{*}{$\boldsymbol{c}_{\mathbf{9}}$ Units } & \multicolumn{3}{c}{ In mol } & \multicolumn{3}{c}{ In \% } \\
\cline { 2 - 7 } & Ac-KL & Ac-MWL-aca & Ac-MWL-mhw & Ac-KL & Ac-MWL-aca & Ac-MWL-mhw \\
\hline G & 2.98 & 6.77 & 4.59 & 46.9 & 59.2 & 45.5 \\
S & 3.37 & 4.67 & 5.45 & 53.1 & 40.8 & 54.5 \\
S/G & 1.13 & 0.69 & 1.19 & & & \\
\hline
\end{tabular}

The methoxyl protons of Ac-KL (3.72) were 20\% less than Ac-MWLs (4.65). The lower amount of methoxyl groups in KL was attributed to demethylation reactions during kraft pulping [21]. The nucleophilic attack of hydrosulfide ions $\left(\mathrm{SH}^{-}\right)$to aryl methyl ether produced catechol and methylmercaptan. Further oxidation of methylmercaptan produced dimethyldisulfide, which gave KL its characteristic odor.

The number of aliphatic and phenolic hydroxyl groups per $\mathrm{C}_{9}$ unit was determined from the corresponding acetyl group signals (2.50-1.60 ppm). For KL, the OAc/OCH $\mathrm{OHole}_{3}$ ratio $=(2.54+2.22) / 3.72=1.28$. Thus, the total $\mathrm{OAc} / \mathrm{C}_{9}$ ratio $=\left(1.24 \mathrm{OCH}_{3}\right) \times(1.28 \mathrm{OAc} / 1$ $\left.\mathrm{OCH}_{3}\right)=1.59$, i.e., the number of aliphatic $\mathrm{OAc} / \mathrm{CH}_{3}=\left(1.24 \mathrm{OCH}_{3} / \mathrm{C}_{9}\right) \times(2.22 \mathrm{OAc} / 3.72$ $\left.\mathrm{OCH}_{3}\right)=0.74$ and the number of phenolic $\mathrm{OAc} / \mathrm{CH}_{3}=(1.24) \times(2.54 / 3.72)=0.85$. Therefore, the number of aliphatic and phenolic hydroxyl groups per $100 \mathrm{C}_{9}$ units of KL was estimated to be 74 and 85, respectively; 178 and 22 for MWL-aca; 181 and 28 for MWL-mhw. As such, the aliphatic hydroxyl group of KL significantly decreased and the aromatic hydroxyl group significantly increased compared to MWL. It was proposed that new phenolic hydroxyl groups were generated as the methoxyl groups were cleaved during kraft pulping.

The presence of increased hydrocarbons, the majority of which were methylene groups, in Ac-KL (0.76) compared to Ac-MWLs (0.31 and 0.19 for acacia and mixed hardwood, respectively) indicated exposure of the methine $(-\mathrm{CH}-)$ or methylene $\left(-\mathrm{CH}_{2}-\right)$ groups after ring opening of $\beta-\beta$ pinoresinol moieties and $\beta-5$ phenylcoumaran moieties and their condensed derivatives.

The main structural change for KL was evident in the acetyl region, wherein Ac-KL contained more aromatic acetyl protons than Ac-MWLs. Meanwhile, Ac-KL contained significantly less aliphatic acetyl protons compared to Ac-MWLs. The high aromatic and low aliphatic contents of KL could be explained by the kraft pulping reactions, such as the $\beta-\mathrm{O}-4$ bond hydrolysis and bond cleavage at the $\beta$ - and $\gamma$-carbon position as shown in Figure 1. A decrease in methoxyl content in Ac-KL was due to demethylation reactions during kraft pulping. 


\section{6. ${ }^{13} \mathrm{C}$ NMR Analysis}

The ${ }^{13} \mathrm{C}$ NMR spectrum of KL are shown in Figure 5 along with the ${ }^{13} \mathrm{C}$ NMR spectra of MWLs from acacia and mixed hardwood which were used as references. The chemical shifts and intensities are listed in Table 8 along with their assignments based on Lüdemann and Nimz [27] and Chen and Robert [28]. Since the ${ }^{13} \mathrm{C}$ NMR spectra were recorded under conditions that did not allow quantification, this analysis provided qualitative information only. The ${ }^{13} \mathrm{C}$ NMR spectra for MWL-aca and MWL-mhw at the aliphatic and aromatic regions were analogous; however, the ${ }^{13} \mathrm{C}$ NMR spectrum for KL showed diminished aliphatic content and elevated aromatic content. This phenomenon was typical for KL since severe structural modifications occurred in the aliphatic and aromatic moieties of lignin during kraft pulping. In addition, demethylation of methoxyl groups and cleavage of $\gamma$-carbon leading to polycondensation resulted in distinctive difference between KL and native lignin.

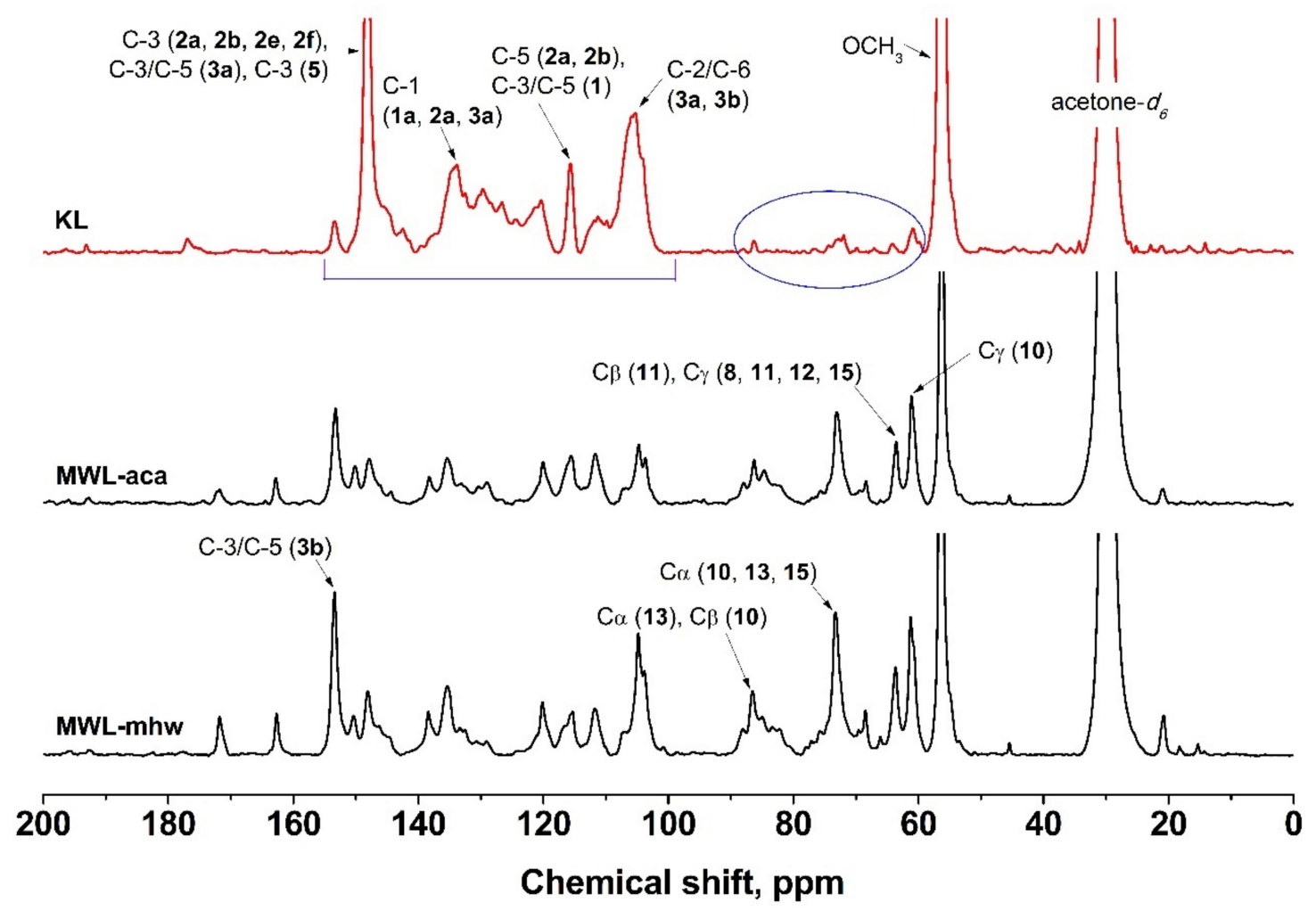

Figure 5. ${ }^{13} \mathrm{C}$ NMR spectra of KL and MWLs.

In MWLs, the presence of carboxyl groups from aliphatic esters (primary alcohols) and $p$-hydroxybenzoate were confirmed at 171.5 and $162.5 \mathrm{ppm}$, respectively, but these peaks were not found in KL since the strongly alkaline environment in kraft pulping easily hydrolyzed the ester bonds.

The aromatic ring resonated in the range of 100 to $160 \mathrm{ppm}$. The most intense peaks in this region for hardwood MWLs were evident at 103.8-104.9 and $153.4 \mathrm{ppm}$, which represented the C-2/C- 6 and C-3/C-5 of etherified syringyl nuclei. These peaks are specific to hardwood guaiacyl-syringyl (GS) lignins [29]. The peak at $153.4 \mathrm{ppm}$ was weak in $\mathrm{KL}$, suggesting decreased methoxyl content due to demethylation or demethoxylation reactions during kraft pulping. In addition, the C-1/C-4 peak of etherified syringyl nuclei at $138.5 \mathrm{ppm}$ was absent in KL, suggesting a high degree of splitting at the $\alpha$-carbon position. 
Table 8. ${ }^{13} \mathrm{C}$ NMR assignment of KL and MWLs.

\begin{tabular}{|c|c|c|c|c|}
\hline \multirow{2}{*}{ Peak, ppm } & \multicolumn{3}{|c|}{ Intensity } & \multirow{2}{*}{ Assignment } \\
\hline & KL & MWL-aca & MWL-mhw & \\
\hline 195.7 & vw & $\mathrm{vw}$ & $\mathrm{vw}$ & $\mathrm{C} \gamma \mathrm{HO}(\mathbf{7}), \mathrm{C} \alpha(\mathbf{1 5})$ \\
\hline 192.6 & vw & vw & vw & $\mathrm{C} \alpha \mathrm{HO}(9)$ \\
\hline 171.5 & - & $\mathrm{w}$ & $\mathrm{m}$ & $\begin{array}{l}\text { Acetyl } \mathrm{C}=\mathrm{O} \text { in } \\
\text { alcohols / phenols }\end{array}$ \\
\hline 162.5 & - & $\mathrm{m}$ & $\mathrm{m}$ & C-4 in $p$-hydroxybenzoate \\
\hline 153.4 & $\mathrm{w}$ & $\mathrm{s}$ & vs & $\mathrm{C}-3 / \mathrm{C}-5(3 \mathbf{b})$ \\
\hline 150.2 & - & $\mathrm{w}$ & $\mathrm{w}$ & $C-4(2 b), C-3(2 d)$ \\
\hline 148.2 & vs & $\mathrm{m}$ & $\mathrm{m}$ & $\begin{array}{c}C-3(2 a, 2 b, 2 e, 2 f), C-3 / C-5(3 a), \\
C-3(5)\end{array}$ \\
\hline 146.3 & $\mathrm{w}$ & $\mathrm{w}$ & $\mathrm{w}$ & $\mathrm{C}-4(2 \mathrm{a}), \mathrm{C} \alpha(6)$ \\
\hline 144.6 & $\mathrm{w}$ & $\mathrm{w}$ & $\mathrm{w}$ & C-4 (4) \\
\hline 138.5 & - & $\mathrm{m}$ & $\mathrm{m}$ & $C-1 / C-4(3 b)$ \\
\hline 135.4 & - & $\mathrm{m}$ & $\mathrm{m}$ & $C-1(2 \mathbf{b}), C 4(3 \mathbf{a})$ \\
\hline 133.6 & $\mathrm{~s}$ & $\mathrm{w}$ & $\mathrm{w}$ & $C-1(\mathbf{1} a, 2 a, 3 a)$ \\
\hline 132.5 & $\mathrm{~s}$ & $\mathrm{w}$ & $\mathrm{w}$ & $C \beta(7)$ \\
\hline 129.9 & $\mathrm{~m}$ & vw & vw & $C-1(2 \mathbf{e}, 4)$ \\
\hline 129.0 & w & $\mathrm{vw}$ & $\mathrm{vw}$ & C-2/C-6 (1), C $\beta(8)$ \\
\hline 126.6 & $\mathrm{~m}$ & - & - & $C-6(2 d)$ \\
\hline 120.3 & $\mathrm{~m}$ & $\mathrm{~m}$ & $\mathrm{~m}$ & $C-6(\mathbf{2 a}, \mathbf{2 b})$ \\
\hline 115.5 & $\mathrm{~s}$ & $\mathrm{~m}$ & $\mathrm{~m}$ & $C-5(\mathbf{2 a}, \mathbf{2 b}), C-3 / C-5(\mathbf{1})$ \\
\hline 111.9 & $\mathrm{w}$ & $\mathrm{m}$ & $\mathrm{m}$ & $C-2(2 a, 2 b)$ \\
\hline 109.9 & $\mathrm{w}$ & - & - & $C-6(2 a, 2 b)$ \\
\hline 107.0 & $\mathrm{w}$ & $\mathrm{w}$ & $\mathrm{w}$ & $C-2 / C-6(3 c, 3 d)$ \\
\hline $104.9-103.8$ & $\mathrm{~s}$ & $\mathrm{~m}$ & $\mathrm{~s}$ & $C-2 / C-6(3 a, 3 b)$ \\
\hline 88.1 & - & $\mathrm{w}$ & $\mathrm{w}$ & $\mathrm{C} \alpha(12)$ \\
\hline 86.6 & - & $\mathrm{w}$ & $\mathrm{m}$ & $\mathrm{C} \alpha(13), \mathrm{C} \beta(10)$ \\
\hline 86.3 & - & $\mathrm{w}$ & $\mathrm{m}$ & $C \beta(10)$ \\
\hline $83.4-81.0$ & - & $\mathrm{w}$ & $\mathrm{w}$ & $C \beta(15)$ \\
\hline 75.0 & $\mathrm{w}$ & $\mathrm{w}$ & $\mathrm{w}$ & $\mathrm{C} \alpha(\mathbf{1 1})$ \\
\hline 73.3 & $\mathrm{w}$ & $\mathrm{s}$ & s & $\mathrm{C} \alpha(10,13,15)$ \\
\hline 63.6 & $\mathrm{w}$ & $\mathrm{s}$ & $\mathrm{s}$ & $C \beta(\mathbf{1 1}), C \gamma(\mathbf{8}, \mathbf{1 1}, \mathbf{1 2}, \mathbf{1 5})$ \\
\hline 61.2 & - & $\mathrm{s}$ & $\mathrm{s}$ & $\mathrm{C} \gamma(\mathbf{1 0})$ \\
\hline 56.4 & vs & vs & vs & $\mathrm{OCH}_{3}$ \\
\hline 20.8 & vw & $\mathrm{w}$ & $\mathrm{m}$ & $\mathrm{CH}_{3}$ in acetyl \\
\hline
\end{tabular}

On the other hand, the peak at $148.2 \mathrm{ppm}$ was very strong for KL. This peak corresponds to C-3/C-5 of non-etherified S units overlapping with the C-3 of etherified and non-etherified $\mathrm{G}$ units. The $\mathrm{C}-3$ of etherified biphenyl (5-5) was also assigned to this peak. Another strong peak from KL at $133.6 \mathrm{ppm}$ was designated to the $\mathrm{C}-1$ of non-etherified $p$-hydroxyphenyl $(\mathrm{H})$, guaiacyl $(\mathrm{G})$, and syringyl (S) nuclei.

The aliphatic groups were situated in the range of 60 to $90 \mathrm{ppm}$. The moderately strong peaks in this region for hardwood MWLs, other than the $\beta-\mathrm{O}-4$ structures, were shown at 73.3 and $63.6 \mathrm{ppm}$. The peak at $73.3 \mathrm{ppm}$ corresponded to the $C \alpha$ of $\beta$ - $\beta$ structures 13,14 . The peak at $63.6 \mathrm{ppm}$ indicated $\mathrm{C} \gamma$ of coniferyl alcohol structures $8, \beta-\mathrm{O}-1$ structures 11, $\beta-5$ structures 12, and $\beta-\mathrm{O}-4$ structures with $\alpha$-carbonyl groups 15 . These peaks were too weak in KL, suggesting loss of these dimeric moieties in KL. The numbered assignments enclosed in a parenthesis in Table 8 denotes the lignin substructures and lignin side chains, which can be found in Figure 6 .

In MWLs, the medium to strong peaks at $86.3,73.3$, and $61.2 \mathrm{ppm}$ were assigned to the $C \beta, C \alpha$, and $C \gamma$ of the $\beta-O-4$ structure, respectively. However, these remarkable peaks in MWLs were almost undetectable in KL due to severe cleavage at the $\alpha-, \beta-$, and $\gamma$-carbons. The cleaved byproducts, such as catechol- or styrene-like structures reacted with the released $\gamma$-hydroxymethyl units derived from $\gamma$-carbon scission to form highly condensed lignin structures. 
<smiles>COCc1ccc(O)cc1</smiles>

1

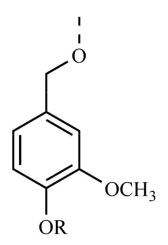

2a: $\mathbf{R}=\mathbf{H}$ 2b: $R=$ Lignin

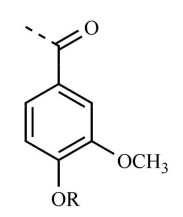

2c: $\mathbf{R}=\mathbf{H}$ 2d: $R=$ Lignin<smiles>CC=Cc1ccc(O)c(OC)c1</smiles>

2e: $\mathbf{R}=\mathbf{H}$ 2f: $R=$ Lignin<smiles>COCc1cc(OC)c(O)c(OC)c1</smiles>

3a: $\mathbf{R}=\mathbf{H}$ 3b: $R=$ Lignin 3c: $\mathbf{R}=\mathbf{H}$

3d: $R=$ Lignin

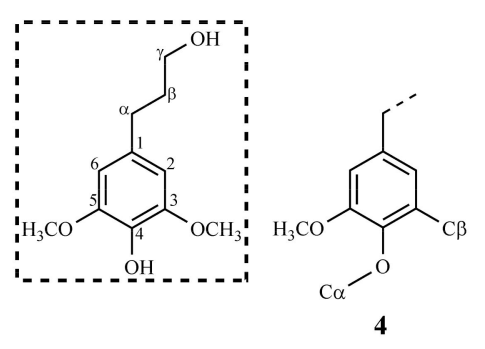<smiles>CCc1cc(CC)c(O)c(-c2cc(CC)cc(OC)c2O)c1</smiles><smiles>O=C(O)/C=C/c1ccc(O)cc1</smiles><smiles>O=C(I)/C=C/c1ccc(O)cc1</smiles><smiles>OC/C=C/c1ccc(O)cc1</smiles><smiles>O=Cc1ccccc1</smiles>
7 8 9<smiles>OCC(OCl)C(O)c1ccc(Cl)cc1</smiles>

10<smiles>OCC(Cl)C(O)c1ccc(Cl)cc1</smiles>

11<smiles>COC(c1ccc(O)cc1)C(C)CO</smiles>

12<smiles>COCC(Cl)C(OCl)c1ccc(O)cc1</smiles>

13<smiles>OCC(Cl)Cc1ccc(O)cc1</smiles>

14<smiles>O=C(c1ccc(O)cc1)C(CO)OCl</smiles>

15

Figure 6. Lignin substructures (1-5) and side chains (6-15) corresponding to ${ }^{13} \mathrm{C} N \mathrm{NM}$ assignments.

\section{Materials and Methods}

\subsection{Materials}

The KL used in this study was kindly provided by Moorim P\&P Co., Ltd. (Ulsan, Korea), the only kraft pulp manufacturer in Korea. The wood chips used in kraft pulping were also provided by the same company. Two types of wood chips, namely, from Acacia spp. imported from Vietnam and mixed hardwood locally available in Korea (50\% Quercus spp. $+50 \%$ other hardwoods), were ground and wood meals which passed through 40-mesh screen were prepared.

The reagents used were ethanol (HPLC grade), benzene (EP), and acetic anhydride (EP) from Duksan Pure Chemical (Ansan, Korea), 1,2-dichloroethane (GR) from Duksan Pharmaceutical (Ansan, Korea), anhydrous ethyl ether (EP) and acetic acid (EP) from Samchun Chemical (Pyeongtaek, Korea), 1,4-dioxane (HPLC grade) from Wako Chemical (Osaka, Japan), pyridine (GR) from Kanto Chemical (Tokyo, Japan), and toluene (HPLC grade) from Fisher-Scientific Korea (Seoul, Korea). The deuterated solvents used were $\mathrm{D}_{2} \mathrm{O}$ (Merck, Darmstadt, Germany), $\mathrm{CDCl}_{3}$ (Eurisotop, Saint-Aubin, France), and acetone- $d_{6}$ (Cambridge Isotope Laboratories, Andover, MA, USA). All reagents were used without further purification.

\subsection{Kraft Pulping and Purification of KL}

KL was obtained from kraft pulping spent liquor, which was discharged from Moorim P\&P's chemical pulping mill facility. Pulping conditions and lignin manufacturing processes for KL were provided by Moorim P\&P. The mixed wood chips contained $50 \%$ acacia and 50\% mixed hardwood. Kraft pulping conditions involved $21-23 \%$ active alkali (as $\mathrm{Na}_{2} \mathrm{O}$ ), $23 \%$ sulfidity, and a pulping temperature of $160-165^{\circ} \mathrm{C}$. Lignin was separated and purified from the black liquor obtained under these pulping conditions by acid precipitation method. Sulfuric acid was added to the black liquor so that the final $\mathrm{pH}$ of the 
mixture reached 9.0. Thereafter, after stirring at $70{ }^{\circ} \mathrm{C}$ for $1 \mathrm{~h}$, lignin was recovered by centrifugal dehydration. The recovered lignin was washed sequentially with $1.5 \%$ dilute sulfuric acid and distilled water (liquid ratio $1: 10,70^{\circ} \mathrm{C}, 1 \mathrm{~h}$ ), and was subsequently dried and pulverized into a powdered form. The yield of KL obtained from the black liquor (33\% solid content) was $9.7 \%$.

\subsection{Chemical Composition of Wood Meal}

For the determination of the chemical composition and the preparation of MWL, $40 \mathrm{~g}$ each of wood meal prepared from acacia and mixed hardwood chips was extracted with 95\% alcohol-benzene (1:2) solvent using a large scale Soxhlet apparatus. The wood meal was extracted with a total of $2 \mathrm{~L}$ solvent at $70-80^{\circ} \mathrm{C}$ for $6 \mathrm{~h}$. After extraction, the solvent was removed in vacuo at $60^{\circ} \mathrm{C}$. The extract was dried overnight in a convection oven at $105^{\circ} \mathrm{C}$. The yield of alcohol-benzene extract was calculated using the equation:

$$
\% \text { alcohol }- \text { benzene extract }=\frac{W_{A B}}{W_{0}} \times 100
$$

where $W_{A B}=$ weight of alcohol-benzene extract $(\mathrm{g})$ and $W_{0}=$ weight of wood meal $(\mathrm{g}$, oven dry weight).

The extractive-free wood meals were air-dried overnight in a fume hood. The wood meals were kept in plastic containers. For MWL preparation, part of the wood meals was thoroughly dried in vacuo in the presence of $\mathrm{P}_{2} \mathrm{O}_{5}$. The lignin content was determined by measuring acid-insoluble lignin (Klason lignin) [30] and acid-soluble lignin [31] in accordance to the TAPPI test method. The total lignin content (TLC) was defined as the sum of acid-insoluble and acid-soluble lignin.

\subsection{Preparation of $M W L$}

The thoroughly dried extractive-free wood meals were used for preparing MWLs. Briefly, $6 \mathrm{~g}$ of wood meal was placed in a 500-mL stainless-steel jar in the presence of toluene. The jar containing the sample was mounted on a vibratory ball mill and treated for $100 \mathrm{~h}$. After milling, the MWLs were prepared according to the Björkman method [32]. The yield of pure MWL was based on the total lignin content and was calculated using the equation:

$$
\% \text { pure MWL }(\text { on lignin })=\left(\frac{W_{\text {pure }}}{T L C \text { in } W_{0}}\right) \times 100
$$

where $W_{\text {pure }}=$ weight of pure MWL $(\mathrm{g})$ and TLC in $W_{0}=$ total lignin content in wood meal $(\mathrm{g})$.

The yields of MWL-aca and MWL-mhw, based on total lignin, were $14.17 \%$ and $19.22 \%$, respectively.

\subsection{Acetylation of Lignin}

Briefly, $1 \mathrm{~g}$ of the thoroughly dried KL and $20 \mathrm{~mL}$ of anhydrous pyridine were added into a $100-\mathrm{mL}$ Erlenmeyer flask. The flask was sonicated for $90 \mathrm{~s}$ to disperse the mixture. Afterwards, $20 \mathrm{~mL}$ of acetic anhydride was added and the mixture was stirred using a magnetic stirrer (SR-306, Advantec, Tokyo, Japan) at room temperature for $48 \mathrm{~h}$. The reaction was quenched by spraying the mixture using a tapered pipette onto an ice bath, containing $350 \mathrm{~g}$ of crushed ice and $400 \mathrm{~g}$ of deionized water (DI-water) in a 1-L beaker, with vigorous stirring using a magnetic stirrer (RCN-7, Eyela, Tokyo, Japan) for $1 \mathrm{~h}$ at room temperature. The Ac-KL was collected by filtration using a nylon 66 membrane filter (47 mm diameter, $0.45 \mu \mathrm{m}$ pore size, Alltech, Lexington, KY, USA). The Ac-KL on the filter was washed with sufficient DI-water and then dried in vacuo for 3 days in the presence of $\mathrm{P}_{2} \mathrm{O}_{5}$.

For the acetylation of MWLs, $50 \mathrm{mg}$ of MWL was dissolved in $1 \mathrm{~mL}$ of pyridine and then $1 \mathrm{~mL}$ of acetic anhydride was added dropwise. For MWL precipitation, 17-18 $\mathrm{g}$ of 
crushed ice and $20 \mathrm{~g}$ of DI-water were used. The filtering, washing, and drying were carried out in the same manner as for Ac-KL.

\subsection{Elemental Analysis}

$\mathrm{C}, \mathrm{H}, \mathrm{N}$, and $\mathrm{S}$ analysis was performed on moisture-free $\mathrm{KL}$ and MWL samples (MWL-aca and MWL-mhw) using an Elemental Analyzer (IT/Flash 2000, Thermo Fisher Scientific, Waltham, MA, USA) at the Center for University-wide Research Facility, Jeonbuk National University (CURF, JBNU). The oxygen composition was calculated as $100-(\mathrm{C}+\mathrm{H}+\mathrm{N}+\mathrm{S})$.

\subsection{Determination of Molecular Weight (MW)}

The average MW of lignins was determined by gel permeation chromatography (GPC). A $2 \mathrm{mg}$ of Ac-lignin was dissolved in $1 \mathrm{~mL}$ of THF in a 10-mL conical beaker. The beaker was sonicated for $5 \mathrm{~s}$ and then filtered through a $0.45 \mu \mathrm{m}$ PTFE syringe filter (Chemco Scientific, Cheongju, Korea). The filtrate was transferred into a 2-mL vial and diluted 10 times with THF. The GPC (Waters, Milford, MA, USA) was conducted at CURF under conditions shown in Table 9.

Table 9. Analysis conditions for GPC.

\begin{tabular}{cc}
\hline GPC Configuration & Waters (Acquity APC) System, Milford, MA, USA \\
\hline Columns & Acquity APC $2.5 \mu \mathrm{m}$ XT $125(4.6 \times 150 \mathrm{~mm}$, Waters, Dublin, Ireland), \\
Flow rate & Acquity APC $1.7 \mu \mathrm{m} \mathrm{XT} 45(4.6 \times 150 \mathrm{~mm}$, Waters, Dublin, Ireland) \\
Sample injection volume & $0.6 \mathrm{~mL} / \mathrm{min}$ \\
Eluent & $10 \mu \mathrm{L}$ \\
Column oven temperature & $30^{\circ} \mathrm{C}$ \\
Detector & $10 \mathrm{~min}$ \\
Analysis time & $\mathrm{UV}(254 \mathrm{~nm}$ : polystyrene standards; $280 \mathrm{~nm}:$ samples $)$ \\
MW polystyrene standards & Blue: $66,000-15,700-3470-474 \mathrm{Da}$ \\
& White: $35,500-9130-2280-266 \mathrm{Da}$ \\
\hline
\end{tabular}

\subsection{FT-IR Analysis}

FT-IR analysis was performed on KL and MWL samples using the attenuated total reflection (ATR) method (4000-500 $\mathrm{cm}^{-1}$ ) with an FT-IR spectrophotometer (Frontier, Perkin Elmer, Shelton, CT, USA) at the CURF, JBNU.

\section{9. ${ }^{1} \mathrm{H}$ NMR Analysis}

A $15 \mathrm{mg}$ of the Ac-KL sample was dissolved in $0.4 \mathrm{~mL}$ of $\mathrm{CDCl}_{3}$ in a $10-\mathrm{mL}$ conical beaker. The beaker was sonicated for 1-2 min to dissolve the sample. The mixture was filtered through a fine glass wool suspended inside a Pasteur pipette, which was directly connected to a clean NMR tube. The conical beaker was rinsed with additional $0.3 \mathrm{~mL}$ of $\mathrm{CDCl}_{3}$ and the contents were transferred as described in previous filtration method. An amount of $10 \mathrm{mg}$ of sample was used for Ac-MWL, and the dissolution and filtration were carried out in the same manner as for the Ac-KL sample. The measurement was conducted using the NMR spectrometer (500 MHz FT-NMR, JNM-ECZ500R, JEOL, Tokyo, Japan) at the CURF, JBNU.

\subsection{0. ${ }^{13}$ C NMR Analysis}

For KL and MWL-mhw, $100 \mathrm{mg}$ of sample was dissolved in $0.7 \mathrm{~mL}$ acetone- $d_{6}$ and $\mathrm{D}_{2} \mathrm{O}$ (9:1) while for MWL-aca, a different solvent ratio, i.e., 8:2, was used. The filtration was carried out in the same manner as for ${ }^{1} \mathrm{H}$ NMR samples. The measurement was conducted using the NMR spectrometer (500 MHz FT-NMR, JNM-ECZ500R, JEOL, Tokyo, Japan) at CURF, JBNU, and a minimum of 10,000 scans were collected. 


\section{Conclusions}

KL had higher carbon content but lower oxygen and methoxyl contents than MWLs. The two MWLs, namely, MWL-aca and MWL-mhw, had almost similar elemental composition, methoxyl content, and $C_{9}$ formula. $K L$ had a $M_{w}$ of about $1 / 4$ and a $M_{n}$ of $1 / 3-1 / 4$ than that of Ac-MWLs. From the results of the elemental analysis, GPC, FT-IR, ${ }^{1} \mathrm{H}$ NMR, and ${ }^{13} \mathrm{C}$ NMR, it was confirmed that the aromatic nuclei and side chains of KL underwent severe structural modifications, such as $\gamma$-carbon cleavage, demethylation, and polycondensation reactions during kraft pulping. Aromatic content increased and aliphatic content decreased in KL. $\beta-\mathrm{O}-4$ moieties were hardly detected since this linkage was extensively cleaved by nucleophilic attack of $\mathrm{SH}^{-}$and $\mathrm{OH}^{-}$during pulping. Therefore, these results could be the basis for future applications of KL produced in Korea.

Author Contributions: Investigation, formal analysis, writing — original draft preparation, J.-S.M.; investigation, formal analysis, writing-review and editing, J.A.P.; conceptualization, investigation, writing-review and editing, supervision, funding acquisition, S.-P.M. All authors have read and agreed to the published version of the manuscript.

Funding: This research was supported by the National Research Foundation of Korea (NRF) grant funded by the Korean government (MSIT) (No. 2020R1A2C2012356).

Institutional Review Board Statement: Not applicable.

Informed Consent Statement: Not applicable.

Data Availability Statement: Most of the data used during the preparation of the manuscript are included in the Results and Discussion sections.

Acknowledgments: The authors would like to acknowledge Moorim P\&P Co., Ltd. for providing $\mathrm{KL}$ and wood chips. The authors would like to appreciate the technical assistance provided by the CURF, JBNU.

Conflicts of Interest: The authors declare no competing interest.

Sample Availability: Samples of the compounds are not available from the authors.

\section{References}

1. Meister, J.J. Modification of lignin. J. Macromol. Sci. Polym. Rev. 2002, 42, 235-289. [CrossRef]

2. Norgren, M.; Edlund, H. Lignin: Recent advances and emerging applications. Curr. Opin. Colloid Interface Sci. 2014, 19, 409-416. [CrossRef]

3. Lora, J.H.; Glasser, W.G. Recent industrial applications of lignins; A sustainable alternative to non-renewable materials. J. Polym. Environ. 2002, 10, 39-48. [CrossRef]

4. Tejado, A.; Pena, C.; Labidi, J.; Echeverria, J.M.; Mondragon, I. Physico-chemical characterization of lignins from different sources for use in phenol-formaldehyde resin synthesis. Bioresour. Technol. 2007, 98, 1655-1663. [CrossRef] [PubMed]

5. Mancera, C.; Ferrando, F.; Salvadó, J.; El Mansouri, N.E. Kraft lignin behavior during reaction in an alkaline medium. Biomass Bioenergy 2011, 35, 2072-2079. [CrossRef]

6. Mun, S.P. Utilization of lignin: Past, present, future. In Proceedings of the KTAPPI, Chuncheon, Korea, 24-25 October 2013; p. 34.

7. Vishtal, A.; Kraslawski, A. Challenges in industrial applications of technical lignins. BioResources 2011, 6, 3547-3568. [CrossRef]

8. Jardim, J.M.; Hart, P.W.; Lucia, L.; Jameel, H. Insights into the potential of hardwood kraft lignin to be a green platform material for emergence of the biorefinery. Polymers 2020, 12, 1795. [CrossRef]

9. Fengel, D.; Wegner, G. Wood-Chemistry, Ultrastructure, Reactions, 1st ed.; Walter de Gruyter: Berlin, Germany, $1984 ;$ pp. 543-555.

10. Hemmila, V.; Adamopoulos, S.; Karlsson, O.; Kumar, A. Development of sustainable bio-adhesives for engineered wood panels-A Review. RSC Adv. 2017, 7, 38604-38630. [CrossRef]

11. Chang, Z.Z.; Yu, B.J.; Wang, C.Y. Lignin-derived hierarchical porous carbon for high-performance supercapacitors. J. Solid State Electrochem. 2016, 20, 1405-1412. [CrossRef]

12. Che, C.; Vagin, M.; Wijeratne, K.; Zhao, D.; Warczak, M.; Jonsson, M.P.; Crispin, X. Conducting polymer electrocatalysts for proton coupled-electron transfer reactions: Toward organic fuel cells. Adv. Sustain. Syst. 2018, 2, 1800021. [CrossRef]

13. Alinejad, M.; Henry, C.; Nikafshar, S.; Gondaliya, A.; Bagheri, S.; Chen, N.; Singh, S.K.; Hodge, D.B.; Nejad, M. Lignin-based polyurethanes: Opportunities for bio-based foams, elastomers, coatings and adhesives. Polymers 2019, 11, 1202. [CrossRef] [PubMed]

14. Bengtsson, A.; Hecht, P.; Sommertune, J.; Ek, M.; Sedin, M.; Sjöholm, E. Carbon fibers from lignin-cellulose precursors: Effect of carbonization conditions. ACS Sustain. Chem. Eng. 2020, 8, 6826-6833. [CrossRef] 
15. Abreu, H.D.S.; Freire, M.D.F.I. Methoxyl content determination of lignins by ${ }^{1}$ H NMR. An. Acad. Bras. Ciênc. 1995, 67, 379-382.

16. Robert, D.R.; Bardet, M.; Gellerstedt, G.; Lindfors, E.L. Structural changes in lignin during kraft cooking Part 3. On the structure of dissolved lignins. J. Wood Chem. Technol. 1984, 4, 239-263. [CrossRef]

17. Sameni, J.; Krigstin, S.; Sain, M. Characterization of lignins isolated from industrial residues and their beneficial uses. BioResources 2016, 11, 8435-8456. [CrossRef]

18. Gierer, J.; Lenz, B.; Wallin, N. The reactions of lignin during sulphate cooking. Part, V. Model experiments on the splitting of aryl-alkyl ether linkages by $2 \mathrm{~N}$ sodium hydroxide and by white liquor. Acta Chem. Scand. 1964, 18, 1469-1476. [CrossRef]

19. Santos, R.B.; Hart, P.W.; Jameel, H. Wood based lignin reactions important to the biorefinery and pulp and paper industries. BioResources 2013, 8, 1456-1477. [CrossRef]

20. Johansson, B.; Miksche, G.E. Über das verhalten des lignins bei der alkalikochung. IV. Der alkalische abbau von arylglycerin- $\beta$ arlyätherstrukturen versuche am isoeugenolglykol- $\beta$-(2-methoxyphenyl)-äther. Acta Chem. Scand. 1969, 23, 924-930. [CrossRef]

21. Sarkanen, K.V.; Chirkin, G.; Hrutfiord, B.F. Base-catalyzed hydrolysis of aromatic ether linkages in lignin: 1. The rate of hydrolysis of methoxyl groups by sodium hydroxide. TAPPI J. 1963, 46, 375.

22. Tolbert, A.; Akinosho, H.; Khunsupat, R. Characterization and analysis of the molecular weight of lignin for biorefining studies. Biofuel Bioprod. Biorefin. 2014, 8, 836-856. [CrossRef]

23. Faix, O. Classification of lignins from different botanical origins by FT-IR spectroscopy. Holzforschung 1991, 45, 21-27. [CrossRef]

24. Lundquist, K. NMR studies on lignin. 2. Interpretation of the ${ }^{1} \mathrm{H}$ NMR spectrum of acetylated birch lignin. Acta Chem. Scand. B 1979, 33, 27-30. [CrossRef]

25. Lundquist, K. NMR studies on lignin. 4. Investigation of spruce lignin by ${ }^{1} \mathrm{H}$ NMR spectroscopy. Acta Chem. Scand. B 1980, 34, 21-26. [CrossRef]

26. Jahan, M.S.; Mun, S.P. Characteristics of dioxane lignins isolated at different ages of nalita wood (Trema orientalis). J. Wood Chem. Technol. 2007, 27, 83-98. [CrossRef]

27. Lüdemann, H.-D.; Nimz, H. Carbon-13 nuclear magnetic resonance spectra of lignins. Biochem. Biophys. Res. Commun. 1973, 52, 1162-1169. [CrossRef]

28. Chen, C.L.; Robert, D. Characterization of lignin by ${ }^{1} \mathrm{H}$ and ${ }^{13} \mathrm{C}$ NMR spectroscopy. In Methods in Enzymology, Biomass, Part B: Lignin, Pectin, and Chitin, 1st ed.; Wood, W., Kellogg, S., Eds.; Academic Press: New York, NY, USA, 1988; Volume 161, pp. 137-158.

29. Nimz, H.H.; Robert, D.; Faix, O.; Nemr, M. ${ }^{13}$ C NMR spectra of lignins, 8. Structural differences between lignins of hardwoods, softwoods, grasses and compression wood. Holzforschung 1981, 35, 16-26. [CrossRef]

30. TAPPC. TAPPI T 222 om-02, Acid-Insoluble Lignin in Wood and Pulp, TAPPI Test Methods. 2006. Available online: http: / / tappi.org/content/SARG/T222.pdf (accessed on 15 March 2021).

31. TAPPC. TAPPI UM 250, Acid-soluble lignin in wood and pulp. In TAPPI Useful Methods; TAPPI Press: Atlanta, GA, USA, 1991.

32. Björkman, A. Isolation of lignin from finely divided wood with neutral solvents. Nature 1954, 174, 1057-1058. [CrossRef] 